Navigations

Cathy Turner.

The blue ribbon of the Sat-Nav unspooled on the dashboard, but only ever showed a fraction of the route. Bengaluru is not an easy city to navigate, with only a few markers that are instantly apparent. We usually started from the North West. If we went past Sankey Tank, we were travelling south. If we were on the airport road, we were going north. If we passed through Cubbon Park, we were heading South West. That was it; there are no mountains, no major rivers, and no coastlines by which to orient oneself. The city has rapidly expanded as a stitched together accumulation of villages, meaning that ideas of what makes such an agglomeration a 'city' often do not work here, with many neighbourhoods retaining a distinct character and their own centre. Our project intends to focus on the geographical pressures on city peripheries, but we keep discovering other ways of considering periphery, some of them inner city. As Nagendra, Unnikrishnan and Sen point out, rural architectures, ecologies and customs can persist even in Bengaluru's oldest urban districts (2014). When ideas of centre and periphery keep failing, how might one navigate?

Performance makes us aware of features that do not appear on Google Maps, and navigates by co-ordinates not identified in any handbook. I was travelling in Bengaluru due to my involvement in a project that looked at performance as intervention on South Indian city peripheries, wherever we might find them.

'Performing the Periphery' is an AHRC funded network of cross-disciplinary scholars, at the National Institute of Advanced Studies in Bengaluru and the University of Exeter in the UK. We are sharing thoughts and observations on the politics of performance on the outskirts of expanding cities, bringing together perspectives from the humanities, social and natural sciences. While the core of our network consists of observations of performances already taking place, during our first phase in Bengaluru, we also commissioned a series of performance walks, each of which chose to navigate different peripheries.

The call for artists specified that the work should seek to engage residents in discussion of their city. This was a testing-ground for considering what kinds of dialogue performance might provoke. We suggested that the artists might consider Bengaluru's remaining 'inscription stones' recently mapped by Udaya Kumar (Kumar 
2017); these stones, some over a thousand years old, are inscribed with the history of the city, often in connection with the areas in which they are found. Of the 160 stones recorded, Kumar has tracked and verified sixty-eight. We were interested in this project, and in both the longevity and failure of the stones' attempt to record placed events for eternity. We asked:

What is memorable, and yet difficult to capture or preserve? What ordinary things go unnoticed?

How could performance or performative elements explore the desire for permanence and inevitability of impermanence in recording the life of a city? (e.g. non-permanent records; repeated acts; video records; use of technology to record actions or overlay images onto place).

How could local people contribute their sense of what is worth recording and/or preserving in their vicinity?

How might this speak to the peripheries of the city and the pressures of urbanisation?

In the event, none of the works directly referenced the inscription stones; however, all of them were knowingly fragmentary and partial mappings of the city. Moreover, they not only provoked dialogue, but all, in a sense, provoked dialogues about dialogue.

\section{Smitha Cariappa}

Artist Smitha Cariappa chose to work in proximity to the two inscription stones at Allalasandra. She showed us the stones, propped up in front of a water tank in the village itself. Though part of Bengaluru, Allalasandra is rural in character, an old village with a new temple surrounded by low dwellings of a rural character. The stones were smeared with kumkum and flowers. An old man told us they were the words of God. Like the Ten Commandments, he said. Then he smiled and admitted they were actually written by human hands.

Smitha's walk did not take place here, but at the nearby Allalasandra Lake, an area that appears to be an oasis of natural beauty until one observes the signs of pollution in the water and the litter outside the fenced-in path. On one side, expensive villas 
hold the best rooftop views. Around the other, there are the homes of migrant workers, heaps of rubbish and half-finished high-rise concrete buildings. It is a site filled with contradictions. Smitha's intention, as she pushes a shopping trolley to navigate the lake's perimeter, is to engage passers-by in dialogue about these tensions. In practice, at $7 \mathrm{am}$, and in these surroundings, no one is ready to talk to her. The air fills with fog, wet-blanketing a brief dialogue with an invited guest. It is only when she inscribes the word 'EAT' in rice on the jetty, and waits for the birds to erase it, that watching children begin to engage. The birds, however, wait on the phone lines for the crowd to disperse and the white ducks have already left for the morning.

It happens. Not every performance works the way you hope it will. Yet this walk, if at times unintentionally, drew attention to the lake path as a controlled and un-convivial space, and to the 'natural' as commodified, constrained and polluted. The birds, squatting like Hitchcock's agents of horror, seemed waiting to remove all human record.

\section{Abhishek Hazra}

In nearby Yelahanka, Abhishek Hazra undertook a peculiar engagement with language. Playing the role of a market researcher for an IT start-up, he worked with Kannada-speakers to engage passers-by in quite lengthy interactions. The initial fiction was that the company, Vacya, was developing voice-recognition software for Kannada (a persuasive idea, not without credibility), yet that Vacya was also working with performers and that this one, Pratya, required help with his Kannada-speaking. Following introduction, the passers-by assisted Pratya in reading aloud. For this, Abhishek chose passages from essays by cultural critic D. R. Nagaraj, an expert in Kannada literature and the Dalit movement. The conversations that followed revolved around language, its placing, its valuation and its meaning.

We watched these encounters for some time on the busy main road opposite the huge statue of Hanuman, where Abhishek cut a strange figure among the hawkers, and beneath the green and white political bunting that was hoisted overhead. After a while, we all crossed the road and walked up past the bus station through quieter streets, where we watched Abhishek and his team engage with a shop owner. We 
left after that, partly driven by the mosquitoes and the necessity of keeping at distance, but the discussions continued, finishing on a bus at $9 \mathrm{pm}$.

Abhishek later showed us video footage, which demonstrated the seriousness with which his respondents corrected his pronunciation. He told us that they did not read the project as one of 'vernacular cosmopolitanism', but rather in terms of the primacy of Kannada, often segueing into questions of morality, traditional values and 'wrong' dress choices. None commented on Dalit politics, though this had happened, explosively, in a trial run (Hazra 2018).

Hazra's work is many-layered and begins to demonstrate the significance of language in this particular city - a significance that is hidden from visitors who speak only European languages. I could not navigate the contours of written or spoken Kannada, Urdu, Tamil, Malayalam, Telugu, Gujurati, Marwari or Hindi as they appeared, or did not appear, or were overheard on the streets we passed through.

For those more proficient than I, the work suggests the gap between the supposed efficiency of Bengaluru's software and its failures with regard to local languages; people's identification with language and the location of Kannada discourse within the city; the ideologies associated with language and its status, current or desired. Language is a formidable periphery, one that is difficult to cross.

\section{$\underline{\text { Maraa }}$}

Media and arts collective Maraa led a walk around the periphery of the campus at St Joseph's College Autonomous in Shantinagar. For some time, they had been working with students at various universities in the city using a 'Radio in a Purse' to record conversations and testimonies about sexual harassment and assault on campus. Finding it difficult to gain access to the campuses themselves to carry out this work, they moved to working in settings just outside the university gates. Now, they had created an audio walk from these recordings, again located on a campus periphery.

The walk combined verbatim testimony with fictionalised dialogue between a young, heterosexual couple, generously suggesting the tensions and confusion on either side. There were also points where the walker was asked to undertake simple actions. In one moment, we stood around a tree, tying knots in a string in answer to 
questions about our own experiences. Once complete, we were invited to tie the string to the tree, and to that of another person - an act of solidarity and acknowledgement. At another moment, we had to hunt through pages of administrative guidelines for students in order to find the single one that referred to a complaints committee. Following this, our guide, Nihil Passanha, explained how dysfunctional such committees are, and how difficult it is for complaints to be heard. Towards the very end of the walk, we teamed up with each other and took it in turns to be led blindfold, as we listened to a further testimony. This proved to be an exercise in trust, and a prelude to a final chat over tea.

The conversation after the walk flowed easily. There was much that it had brought up, many aspects to be acknowledged, considered, and argued over. On the occasion when I was there, this included a discussion of the fictional couple's depiction, questions of humour and difficulties of raising concerns. This conversation, often suppressed, is an end in itself, since Passanha and Angarika Guha explained that many challenges 'are not addressed even within the students' own discourse', and that the walk might create interactions between different kinds of students, not usually exchanging thoughts about these matters. These are small steps towards effective measures to address the issues.

The choice of the audio walk was a deliberate move away from the dominance of visual material to approach issues of gender inequality and sexual harassment. Spoken into the ear, these private conversations were experienced in public space. By routing the walk around the university, Maraa placed these concerns into the everyday spaces in close proximity to the campus, quite literally bringing them out into the open. The location highlights, too, the idea that 'these conversations are at the margins of college priorities' (Guha and Passanha 2018). It subverts these familiar collage spaces, emphasising that this too happens here.

\section{Lawai BemBem}

In Church Road, playwright, performer and director Lawai BemBem engaged Science Fiction readers in pursuit of the alien. As an artist who works 'between India and Manipur', her response to ideas of periphery were to reference the nation's borders (Lawai 2018). Considering the 'trust-deficient society' that is created when 
some humans are considered to be 'aliens', she wondered about the entry points to this for the Sci-fi fans she knew.

In this first iteration of her project, she met her audiences in Blossoms book shop, working with small numbers. She asked them to make rough translations from selected paragraphs in chosen books, read aloud to partners who could not understand. BemBem then asked the listeners to interpret from what was read aloud to them. Through various twists of alienation and interpretation, the walkers would arrive at another bookshop and finally a café, for discussion and coffee.

Since most Bengalureans speak more than one language, the 'translations' often meant the use of a 'mother tongue', a language other than the English framing the walk. For some, it was this tongue itself, little used, that felt alien, a discovery of an alienation within the self; yet at the same time, they felt it as an acquisition of an expertise in relation to the uncomprehending listener, and thus a way of coming home to the language. For me, struggling with French, so far from my mind that week, it was a sense of my own thoughts being alienated from me, and made distant, while listening without comprehending was a less disorienting exercise. In all the various twists and turns, the leaps of interpretative guesswork, improvisation, failed connection or failed articulation did provide a textured sense of the reliance on assumption, imperfect expertise and approximation that often guides our experiences of others.

Having engaged the walkers in a stroll between bookshops and between understood and not understood languages, BemBem sat with them over coffee and asked what passages from their reading were reminiscent of this. My response was to remember William Gibson's Pattern Recognition, with its themes of the desire for meaning, and reaction to symbols. Through this conversation, BemBem sought to connect these fictional experiences with moments of disconnection, alienation and incomprehension in the real city. Finally and gently, in presenting us each with a packet of sunflower seeds, she connected the performance to the 'North Eastern state' of Manipur (this terminology is contested), and questions of migration and the 'alien' incomer.

In describing this work later, BemBem suggested that in thinking about Manipur, and about India as a whole, one is considering not 'periphery' so much as 'frontier'. The 
substitution of one word for another draws attention to the inherent violence in all policing of peripheries, metaphorical or literal.

These artists, then, led us on walks that navigated the barren perimeters of a lake; the rivers of divergent literatures; the heights and hidden chasms of academia and the frontiers of identity that fracture the city and even the self. Between them, they began discussions of urban development and ecology, language-based ideology and the dynamics of the IT industry, gender inequality and campus discourse, and local or national identity, as they are experienced in specific areas of Bengaluru. There was no attempt at a more comprehensive navigation, nor could there be. Their work does, however, identify and begin to probe a few of the most crucial features of Bengaluru's cultural, as well as geographical landscape.

In particular, it is noticeable that each walk records and marks the peripheries of discourse, the frictions between languages, literatures, registers and voices, and the failures of language, too, fenced in behind protective wire. This Bengaluru is not one that I can know myself, or not to a great extent. I look forward, however, to the further development of this work, which is likely to extend the various enquiries towards deeper and fuller understanding.

\section{'Performing the Periphery' is supported by the Arts and Humanities Research}

Council, and is a research network to study the politics of performance on the urban periphery in South India. It combines scholars from NIAS, Bengaluru and the University of Exeter, with project partners at MOD Institute of urban research, Berlin/Bengaluru.

Guha, Angarika and Nihal Passanha (2018), 'Radio in a Purse', paper given at 'Performing the Periphery' Symposium, NIAS, Bengaluru, $20^{\text {th }}$ February.

Lawai, BemBem (2018), paper given at 'Performing the Periphery', Symposium, NIAS, Bengaluru, 20 th February.

Harini Nagendra, Hita Unnikrishnan and Sreerupa Sen (2014) 'Villages in the City: Spatial and Temporal Heterogeneity in Rurality and Urbanity in Bangalore, India', Land, 3(1), 1-18. 
Hazra, Abhishek (2018), 'A Distant Homage', paper delivered at 'Performing the Periphery', Symposium, NIAS, Bengaluru, $20^{\text {th }}$ February.

Kumar, Udaya (2017), 'Inscription Stones of Bangalore: A Physical Verification Project', found at https://www.scribd.com/document/356763365/Stone-Inscriptionsof-Bangalore, date of access March $1^{\text {st }} 2018$. 